\title{
Investigating Parameters That Effect to Wear of Plasma Nozzle
}

\author{
Paphakorn Pitayachaval ${ }^{1}$ and Muhammatsoifu Sato ${ }^{2}$ \\ ${ }^{1}$ School of Industrial Engineering, Institute of Engineering, Suranaree University of Technology, Nakhon Ratchasima 30000, Thailand \\ ${ }^{2}$ School of Industrial Engineering, Institute of Engineering, Suranaree University of Technology, Nakhon Ratchasima 30000, Thailand
}

\begin{abstract}
Plasma cutting machine normally applies to cut metal in electrical conductivity industrial according to an accuracy dimension and rapidly time consuming. A quality of this process is depend upon a cutting surface and kerf by controlling diameter of nozzle and size of electrode. Since kerf shape is crated base on nozzle diameter, while electrode is served plasma arc. This paper presents an investigating three cutting parameters: cutting speed, pressure gas, current ampere that affect to wear of plasma nozzle. The fixed variables are a plasma-cutting machine, Hypertherm powermax $45 \mathrm{xp}$, Bindee control CNC machine and specimens (100x100 mm.). The cutting speed was holed at 200,300, $400 \mathrm{~mm} / \mathrm{min}$. The gas pressure was controlled at 6, 7, 8 bar. The current Ampere was handled at 40, 42, $45 \mathrm{~A}$. The diameters of nozzle was measured using digital microscope. The experiments conducted based on ANOVA to establish the relationship of those parameters. The nozzle wear depended upon the current Ampere, the high gas pressure while the cutting speed was not effect to nozzle wear.
\end{abstract}

\section{Introduction}

A metal cutting process is wildly used in general industry to cut several metal spare parts and framework such as railway, aircraft, automobile, etc. Even through there are a variety of metal cutting machines such as laser cutting, oxy-fuel gas cutting, water-jet cutting, these machine provide a cutting edge quality that contradicts with product cost. The laser cutting gives a high quality while demand more expend. However, a plasma-cutting machine gives acceptable cutting quality and production time while the product cost is admitted [1].

The plasma cutting machine is a machine to cut metal with high temperature [2]. This machine contains DC power source, pressure plume and cutting head, which composes of torch (cathode), electrode and nozzle, as shown in figure 1 . The plasma art is conducted by heated gas based on extremely high temperature [3], then it transfer via nozzle to work pieces that becomes electrically conductive. After that, the metal is to be melted and removed along cutting pattern. An advantage of plasma cutting is a clean process [4] that produces dross free with minimal heat input. Plasma arc frame is conducted by nitrogen gas and oxygen gas. This frame can be used to cut a conductive material including ferrous and nonferrous metal. Since there are several parameters of acceptable quality for plasma cutting such as cutting speed, current ampere, height of cutting head and gas pressure [5]. To control process parameters that are affects quality of cutting; there are only three key parameters; cutting speed, current ampere and gas pressure, respective [6].
Beside those parameters, heat of plasma gas, Generated by the plasma beam during the cutting operation, also conducts wear of plasma device components, especially nozzle wear for the consumable part [7]. This wear introduces inconstancy frame diameter. In order to obtain the acceptable cutting quality, larger orifice nozzle and electrode were applied [8]. Moreover, variable factors that affect tool life of nozzle and electrode depended upon many factors that are a number of cutting pierces, cutting duration, material thickness [9], including degree of erosion of the nozzle around the orifice nozzle [10]. To investigate those parameters, this paper attempts to conduct experiments for cutting speed, pressure gas, and current ampere in order to identify state of parameters that affect to wear of plasma nozzle.

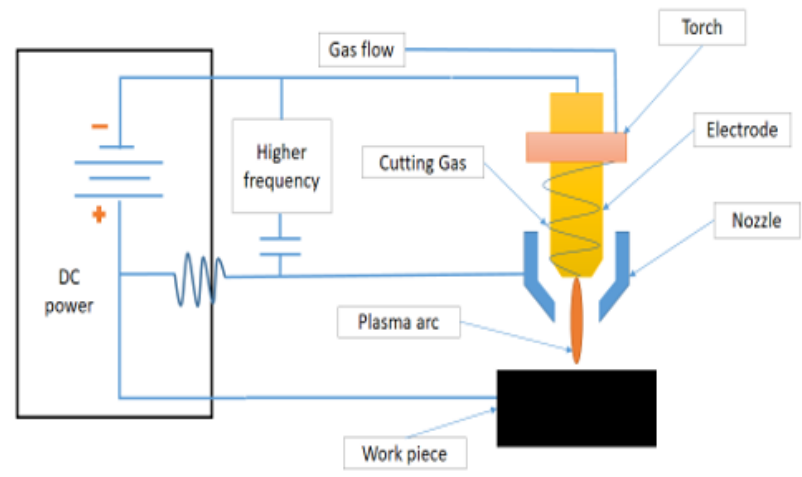

Figure 1. Schematic diagram of plasma arc cutting. 
Table 1. The factors comparison of fuel-gas cut, laser cut and plasma cut from [11]. (Publication Section 5: Electromagnetic Heating Department of Alternative Energy Department and Efficiency http://www.dede.go.th)

\begin{tabular}{|c|c|c|c|}
\hline Machine & Fuel-gas cut & Laser cut & Plasma cut \\
\hline Quality cut & $\begin{array}{l}\text { Pool cut quality get } \\
\text { most burns and } \\
\text { Finishing work piece }\end{array}$ & $\begin{array}{l}\text { best cut quality get minas } \\
\text { burns }\end{array}$ & $\begin{array}{l}\text { Good cut quality get } \\
\text { burns }\end{array}$ \\
\hline Cut speed & Quite slowly & Fast $($ cut $<0.25$ in $)$ & Fast \\
\hline Machine price & $\begin{array}{l}\text { Around } 200,000- \\
500,000 \text { for machine } \\
\text { cut metal diameter } \\
20 \times 6.5 \mathrm{ft} .0 .4 \text { in } \\
\text { thickness }\end{array}$ & $\begin{array}{c}\text { Around } 300,000 \text { for } \\
\text { machine cut metal } \\
\text { diameter } 20 \times 6.5 \mathrm{ft} .0 .4 \text { in } \\
\text { thickness }\end{array}$ & $\begin{array}{l}\text { Around } 120,000 \text { for } \\
\text { machine cut metal } \\
\text { diameter 20x6.5 ft } .0 .4 \\
\text { in thickness }\end{array}$ \\
\hline Consultable & Tip cutter & $\begin{array}{c}\text { Protective glass, gas } \\
\text { nozzle } \\
\text { Dust filter }\end{array}$ & $\begin{array}{l}\text { Cutting nozzle, } \\
\text { electrode }\end{array}$ \\
\hline
\end{tabular}

\section{Experimental}

There are three factors that were investigated on this experimental: current ampere, cutting speed, gas pressure. The current ampere (40, 42, 45A), cutting speed (200, $300,400 \mathrm{~mm} / \mathrm{min})$ and gas pressure $(6,7,8$ bar) ware applied to cut metal (588GrA, 242 Type I) $10 \mathrm{~mm}$. thickness. The cutting parameters were established as presented in Table 2 .

Table 2. The cutting parameters for experimental

\begin{tabular}{|c|c|c|c|c|c|}
\hline \multirow{2}{*}{ Factor } & \multirow{2}{*}{ Symbol } & \multicolumn{3}{|c|}{ Level } & \multirow{2}{*}{ Unit } \\
\hline & & 1 & 2 & 3 & \\
\hline $\begin{array}{l}\text { Current } \\
\text { Ampere }\end{array}$ & A & 40 & 42 & 45 & A \\
\hline $\begin{array}{c}\text { Gas } \\
\text { Pressure }\end{array}$ & B & 6 & 7 & 8 & bar \\
\hline $\begin{array}{l}\text { cutting } \\
\text { Speed }\end{array}$ & $\mathrm{C}$ & 200 & 300 & 400 & $\mathrm{~mm} / \mathrm{min}$ \\
\hline
\end{tabular}

The experimental machine was the Hypertherm powermax $45 \mathrm{xp}$ and the head moving control unit was applied Bindee control, as show in Fig 2. The size of specimens were $100 \mathrm{~mm} \times 100 \mathrm{~mm}$, as show in Fig 3. A digital microscope model Keyence VHX 700F was applied to measure diameter of nozzles after cutting, as show Fig 4.

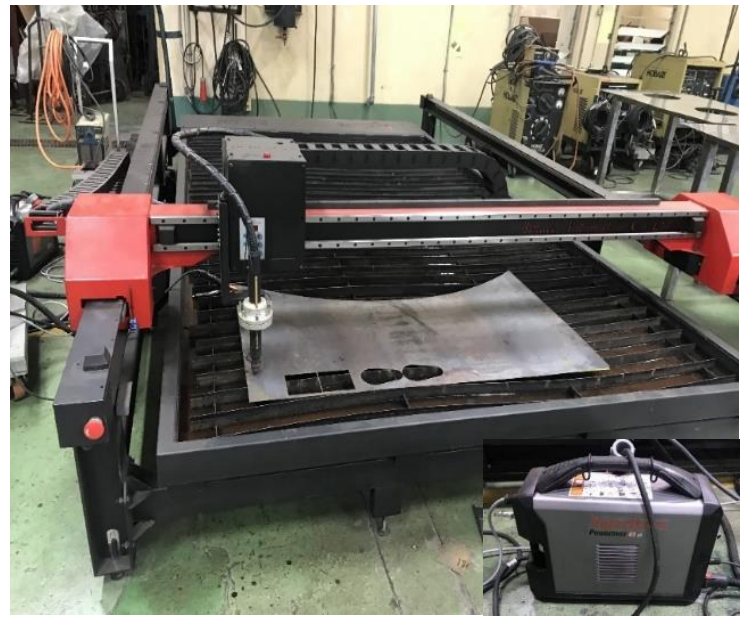

Figure 2. Plasma cutting machine, bindee control.

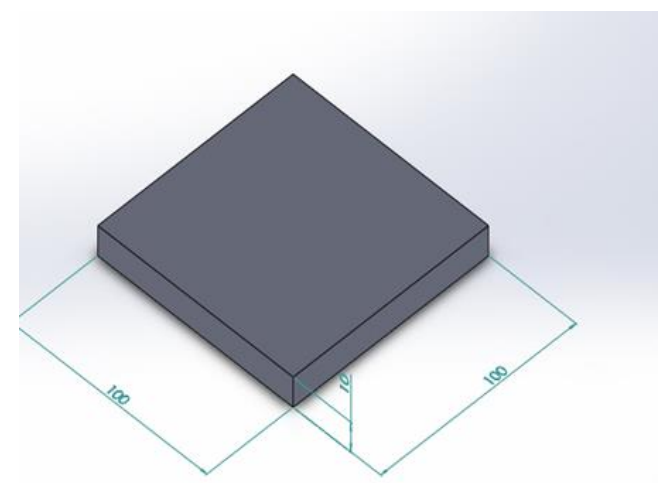

Figure 3. The size of specimen 


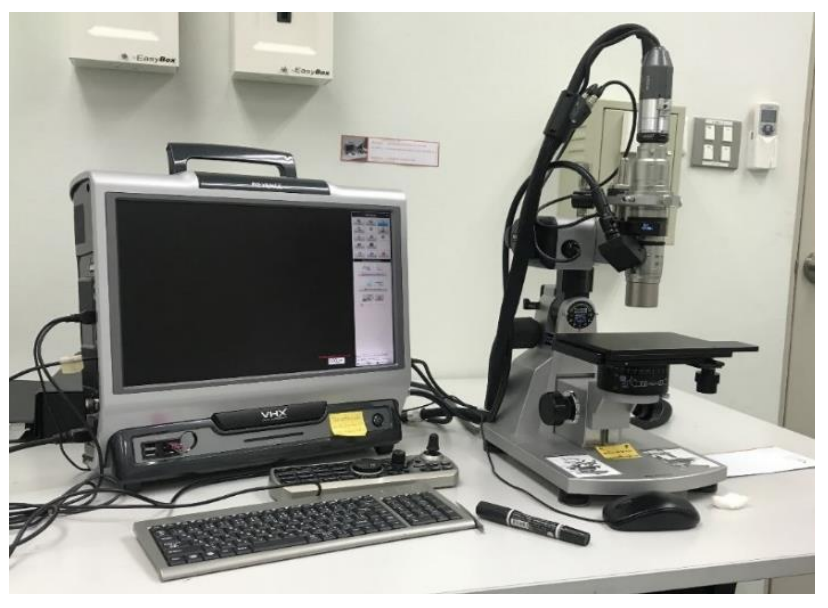

Figure 4. Digital microscope Keyence VHX 700P.

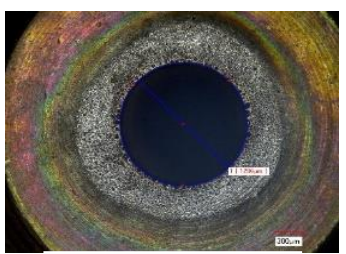

Current ampere $42 \mathrm{~A}$

Gas pressure 7

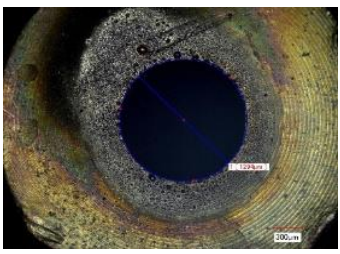

Current ampere $40 \mathrm{~A}$

Gas pressure 7

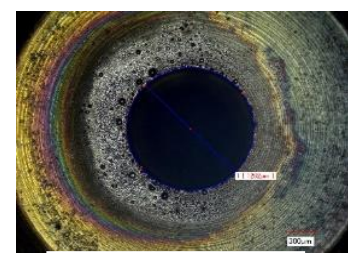

Current ampere $40 \mathrm{~A}$

Gas pressure 8

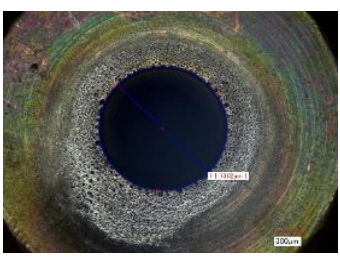

Current ampere $45 \mathrm{~A}$

Gas pressure 7
Figure 5. The variation of orifice nozzle.

\section{Result}

Based on single parameter plasma cutting, the wear of orifice nozzle depended on current ampere and gas pressure, respectively. Beside, two factors analysis founded the interaction between current ampere and gas pressure that effect to wear orifice nozzle, as shown in Table 1. The results of the experiment was obtained from twenty-seven examples, which measure the orifice diameter to check the wear by a digital microscope, as shown in figure 5. Minitab statistic software was applied to analyze interaction effects of those parameters, as shown in table 3.
Table 3. ANOVA analysis by minitab software

\begin{tabular}{|l|r|r|r|r|r|}
\hline \multicolumn{1}{|c|}{ Source } & DF & Adj SS & Adj MS & F-Value & P-Value \\
\hline Current ampere & 2 & 0.000045 & 0.000023 & 0.62 & 0.562 \\
\hline Gas pressure & 2 & 0.000070 & 0.000035 & 0.96 & 0.423 \\
\hline Cutting speed & 2 & 0.000386 & 0.000193 & 5.27 & 0.035 \\
\hline $\begin{array}{l}\text { Current ampere*Gas } \\
\text { pressure }\end{array}$ & 4 & 0.000079 & 0.000020 & 0.54 & 0.714 \\
\hline $\begin{array}{l}\text { Current } \\
\text { ampere } \\
\text { speed }\end{array}$ & 4 & 0.000155 & 0.000039 & 1.06 & 0.437 \\
\hline $\begin{array}{l}\text { Gas } \\
\text { pressure* } \\
\text { speed }\end{array}$ & 4 & 0.000371 & 0.000093 & 2.53 & 0.123 \\
\hline Error & 8 & 0.000293 & 0.000037 & & \\
\hline Total & 26 & 0.001399 & & & \\
\hline
\end{tabular}

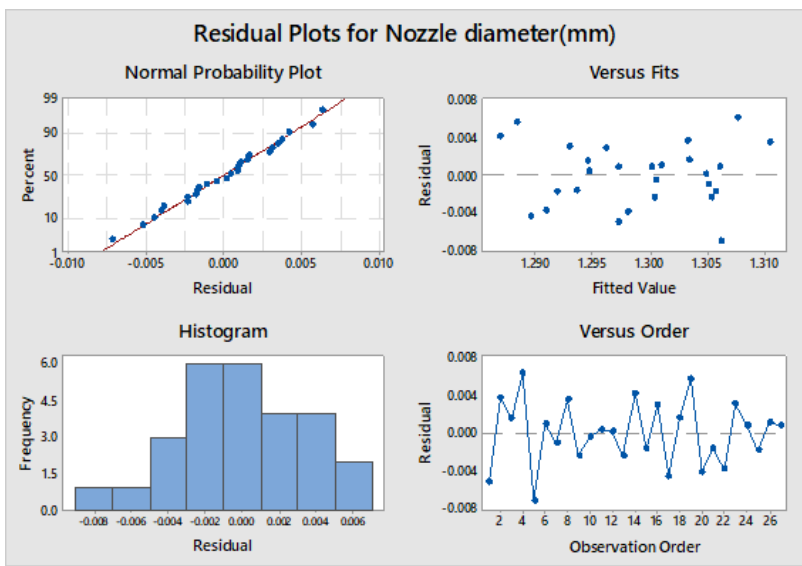

Figure 6. Residual Plots for Nozzle diameter.

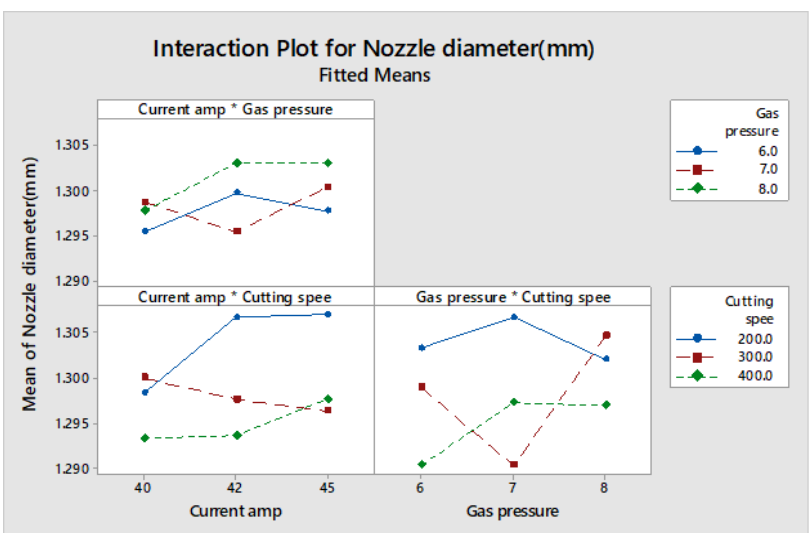

Figure 7. Interaction plot Nozzle diameter. 


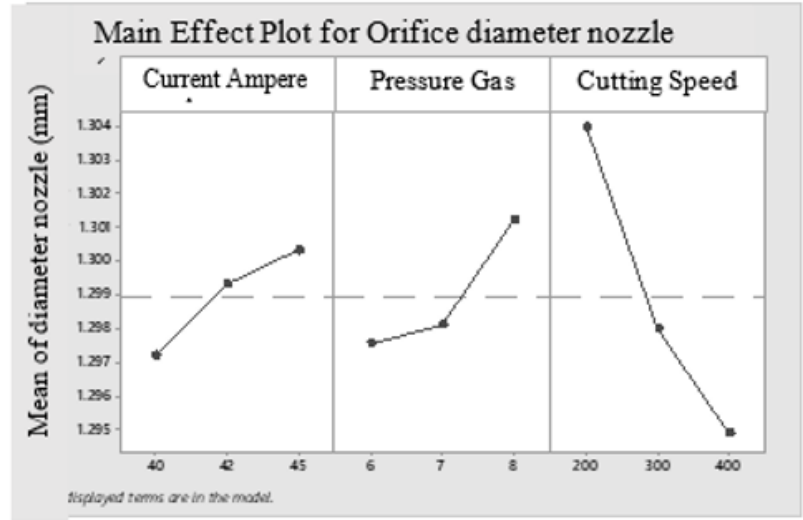

Figure 8. Main effect plots for orifice nozzle diameter.

The normal probability graphs obtained from the experiment presents the normal probability of variable, as shown in figure 6 , in which the variable values are near the ideal normal line, the data from the experiments was distributed under the variation of natural causes. However, the current ampere, gas pressure and cutting speed was interaction, as shown in fig 7.

From Fig 8 The results shown that cutting speed were increased from 200 to $300 \mathrm{~mm} / \mathrm{min}$ and from 300 to 400 $\mathrm{mm} / \mathrm{min}$ the orifice nozzle damaged diameters were decreased rapidly. Moreover, plasma gas pressure were controlled to increase from 6 to 7 bar and from 7 to 8 bar, the orifice nozzle damaged diameter were also expanded. When current amperes were increased from 40 to $42 \mathrm{~A}$ and from 42 to $45 \mathrm{~A}$, the orifice nozzle damaged diameter were also increased, as shown in figure 8 . Therefore, the increasing of controlled parameters effect to the orifice nozzle damaged diameter.

\section{Conclusions}

For plasma cutting, the parameters that affects to nozzle wear were cutting speed, plasma gas pressure and current ampere. These parameters were also presented their interactions for increasing the orifice nozzle damaged diameter. However, the relationship of those parameters will be mathematical defined as the future work.

\section{Acknowledgment}

This research has been supported by the research and development supporting fund, Suranaree University of Technology.

\section{References}

1. Plasma Arc Cutting Cost S.M. Ilii1*, M. Coteaţă $1 * *$ 2009

2. Parametric Study On Plasma Arc Cutting Of Al 6063 Hardik Dholakiya1, Vikas Gondalia2 2017
3. Plasma Cutting In Atmosphere And Under Water W. Bach And A. Gruchow 1992

4. Faq: What Are The Advantages And Disadvantages Of The Principal Cutting Https://Www.TwiGlobal.Com/Technical-Knowledge/Faqs/Faq-WhatAre-The-Advantages-And-Disadvantages-Of-ThePrincipal-Cutting-Process/

5. (Experimental Investigation Of The Plasma Arc Cutting Process , K. Salonitisa, ${ }^{*}$, S. Vatousianosb 2012 )

6. Analysis In Plasma Arc Cutting Of $21 \mathrm{Cr}$ Ferritic Stainless Steel H.Ravi Kumar And S.Thileepan 2015

7. Nozzle And Method Of Operation For A Plasma Arctorch (Richard W. Couch, Jr., Hanover; Nicholas A. Sanders, Norwich; Lifeng Luo, Lebanon; John Sobr, Enfield; Patrik Backander, Lebanon, All Of N.H. 1992)

8. A Review On Nozzle Wear In Abrasive Water Jet Machining Application H. Syazwani1, G. Mebrahitom, A. Azmir 2016

9. Optimizing Consumable Life In Mechanized Plasma Cutting online

Http://Www.Thefabricator.Com/Article/Plasmacutti ng/Optimizing-Consumable-Life-In-MechanizedPlasma-Cutting

10. Detecting Non-Symmetrical Nozzle Wear Naplasmaarc Torch Maciej Wlodzimierz Rogozinski.Bulleen; Subramania Ramakrishnan,Balwyn North; Ashley Grant Doolette,Wishart, All Of Australia; Nicholas A.Sanders, Norwich, Vt.; Richard W.Couch, Jr.. Hanover, N.H. 1998

11. Publication Section 5: Electromagnetic Heating Department Of Alternative Energy Department And Efficiency

Http://Www.Dede.Go.Th 